Article

\title{
Inspiriting Innovation: The Effects of Leader-Member Exchange (LMX) on Innovative Behavior as Mediated by Mindfulness and Work Engagement
}

\author{
Rowan Mulligan ${ }^{1}$, José Ramos ${ }^{2, *(\mathbb{D},}$, Pilar Martín ${ }^{3}$ and Ana Zornoza ${ }^{1}$ (D) \\ 1 IDOCAL, University of Valencia, 46010 Valencia, Spain; rmulligan18@students.claremontmckenna.edu (R.M.); \\ Ana.Zornoza@uv.es (A.Z.) \\ 2 IDOCAL, University of Valencia and IVIE, 46010 Valencia, Spain \\ 3 Department of Psychology and Sociology, University of Zaragoza, 50009 Zaragoza, Spain; pimartin@unizar.es \\ * Correspondence: ramosj@uv.es; Tel.: +34-963983610
}

Citation: Mulligan, R.; Ramos, J.; Martín, P.; Zornoza, A. Inspiriting Innovation: The Effects of LeaderMember Exchange (LMX) on Innovative Behavior as Mediated by Mindfulness and Work Engagement. Sustainability 2021, 13, 5409. https:// doi.org/10.3390/su13105409

Academic Editor: Sangkyun Kim

Received: 25 March 2021

Accepted: 5 May 2021

Published: 12 May 2021

Publisher's Note: MDPI stays neutral with regard to jurisdictional claims in published maps and institutional affiliations.

Copyright: (c) 2021 by the authors. Licensee MDPI, Basel, Switzerland. This article is an open access article distributed under the terms and conditions of the Creative Commons Attribution (CC BY) license (https:// creativecommons.org/licenses/by/ $4.0 /)$.

\begin{abstract}
Continuous innovation has become a key to gaining a sustainable competitive advantage for organizations in the 21st century. By focusing on the underlying mechanisms (i.e., mindfulness and work engagement) by which it works, this study addresses the quality of leader-member relationships and their relevance for innovation in the workplace. Using a sample of 210 employees from 17 Spanish companies, a two-wave longitudinal design evaluated the mediational roles of mindfulness and engagement between leader-member exchange (LMX) quality and innovative work behavior (IWB) in an organizational context. Over the course of a year, two questionnaires were administered to measure LMX quality, mindfulness, engagement, and IWB. Results from structural equation modeling provided support for the hypothesized double-mediation model with a significant full double mediation. Findings suggested that mindfulness and engagement could be characteristic mechanisms of high-quality LMX that helps to facilitate innovation. Practical implications include its creative value in gaining a competitive edge over market competitors and helping organizations to find a sustainable source for their consistent growth through their human capital and innovative potential.
\end{abstract}

Keywords: leader-member exchange; mindfulness; work engagement; innovative work behavior

\section{Introduction}

Continuous innovation has become a key to gaining a sustainable competitive advantage for organizations in the 21st century, set in the context of rapidly changing markets driven by constant technological advances [1-4]. The research field has already recognized the value of human capital and human relationships as some of the sources of innovation and competitive advantage across industries and countries [5-8]. Leadership has been attributed to leaders affecting behavioral changes among their employees in that leaders have the potential to inspire their employees to perform well and achieve organizational goals in competitive markets [9]. Mindfulness has become more salient in recent years and has been shown to increase market agility and strategic creativity $[10,11]$. Furthermore, mindfulness has been conceptualized as a strategy for sustainable competitive advantage, especially throughout the COVID-19 global pandemic [12]. Whereas there are numerous studies that link leadership (LMX) and innovation, only a few studies appeared recently linking LMX and innovation with mindfulness. Nevertheless, until now, research on innovation had not simultaneously included these variables as predictors of innovative behaviors, nor the relationships between leadership and mindfulness. By focusing on the underlying mechanisms (i.e., mindfulness and work engagement) by which it works, this study addresses the quality of leader-member relationships and their relevance for innovative behavior in the workplace. 
Our study aims to integrate in the same study three relevant antecedents of innovative behaviors that had not yet been included in a single research study. In addition, it also aims to explain how high-quality relationships between employees and their supervisors lead to increased innovative behaviors. This study's findings could contribute not only important theoretical developments to the fields of leadership, mindfulness, and innovation, but also practical implications to the (modern and innovative) workplace. To meet the ever-increasing innovation demands in the business market and workplace context, organizations could be assured that high-quality leadership relationships and mindfulness could facilitate engagement and innovation among their employees. They could integrate this knowledge into their organizational strategy to consistently maintain a competitive edge above their market competitors in the long run while maintaining the well-being of employees through work engagement.

\section{Literature Review}

The leader-member exchange (LMX) theory uses a relationship-based perspective of the leadership process. Based on role theory, LMX posits that leaders and followers undergo a role-making process in which differentiated roles result in various relationships ranging from high-quality socio-emotional to low-quality transactional $[13,14]$. The fundamental concept of the LMX theory is that the most effective leadership processes emerge when leaders and followers cultivate mature, high-quality relationships [15]. That is, this theory posits that effective leadership is realized through this dyadic relationship that is developed through a series of social exchanges of various tangible and intangible resources (e.g., leader: information, influence, desired tasks, decision latitude, support, and attention; member: task performance, commitment, loyalty, and citizenship behavior) [16].

Low-quality LMX, which was originally named "out-group relationships," is based on the legal job contract and often implicates transactional leadership behaviors. On the other hand, high-quality LMX, which was originally named "in-group relationships," transcends the formal employment contract and tends to include transformational leadership behaviors [16]. For instance, high-quality LMX relationships may include leaders providing followers with rich resources, such as support autonomy and decision-making latitude $[17,18]$. Meta-analyses have found that higher-quality LMX relationships are associated with better job performance [19] and extra-role performance, such as organizational citizenship behavior [20].

Previous research suggested relationships between LMX and innovative behavior. Leadership sets the critical psychological context to cultivate group climates of innovation. Organizational climate refers to the set of shared perceptions and descriptive beliefs of the work setting [16]. Leaders can be thought of as "climate engineers" [21] who play a key role in molding employees' climate perceptions [22]. That is, leaders have the power to shape employees' perceptions of support or other climate facets in the work environment. This leadership-climate relationship is supported by previous literature [23-25]. Leadership styles have also predicted innovation climate. Pons and Ramos [26] found that inspirational motivation and individualized consideration, two components of transformational leadership, were the first and third highest predictors of innovation climate. Further studies found an interaction effect between LMX quality and LMX differentiation on innovation climate [27] and found LMX to fully mediate the relationship between transformational leadership and organizational citizenship behaviors [28]. Just as organizational citizenship behaviors, innovative behaviors can be conceptualized as another type of extra-role performance $[29,30]$.

Climate perceptions, established by leadership, have been antecedents of appropriately deemed behavior [31]. An evidence-based model explained the way in which LMX affects climate perceptions and subsequent behaviors through a mediation relationship of leadership-climate-injury [32]. High-quality relationships (i.e., high-quality LMX) increase the leader's concern for her or his members' welfare [33-35]. These high-quality relationships are reciprocal [36] and lead to a balanced social exchange [37] in which both parties 
support the goals of the other party, which facilitates mutual concern [38]. Transformational leadership, associated with high-quality LMX and more intimate and personalized relationships, which consist of a higher level of concern for group members' welfare, promote supervisory safety practices [32]. This, in turn, creates higher safety climates, which leads to safer behavior, relationships supported by the integrative framework in which LMX quality would positively affect positive climate perceptions, cultivates climate strength, and facilitates similar perceptions among supervisors and subordinates [24]. To further support this framework, LMX quality, which can be defined as the level of within-group agreement of climate perceptions, has been associated with climate strength [22].

Previous research has empirically supported the positive predictive relationship between LMX on the individual dyadic level and innovation [39-41]. It should be noted that there is a difference between creativity and innovation. Creativity refers to "the production of novel and useful ideas in any domain," whereas innovation includes "the successful implementation of creative ideas within an organization" [42] (p. 2). LMX has a historically positive relationship with creativity $[43,44]$. Multiple researchers have found LMX to predict creative work involvement $[43,45]$. However, it should be noted that the previous LMX-creativity correlations have been variable and the initial studies' creativity operationalizations have not been consistent (i.e., no distinction between creativity and creative work involvement) [43].

With respect to the relationship between high-quality LMX and innovation, a metaanalysis found that LMX quality was positively related to creativity and innovative follower behavior [46]. Employee satisfaction with HR practices mediated the relationship between LMX and innovative behavior [40]. This relationship is logical since creative workplaces are characterized by their capacity to create intrinsic motivation within their employees so that they transcend extrinsic motivators (e.g., financial rewards, competition) [47]. That is, the predictive relationship between high-quality LMX and innovative behavior, which has been supported by previous literature, is rational. The leader possesses the ability to establish and influence places, processes, and relationships that inspirit innovation [48].

The relationships between LMX and mindfulness had recently gained interest from organizational researchers. The high-quality relationships set forth by LMX create the necessary context to facilitate mindfulness within the workers [49] (p. 729). One study proposed a mediational model between leader mindfulness (predictor), LMX quality (mediator), and employee performance (criterion), seeking to close the research gap to establish a predictive link between LMX quality and employee (i.e., member/follower) mindfulness [50].

Mindfulness has become an increasingly popular tool in the organizational setting [51]. There are two main streams of mindfulness research led by Kabat-Zinn and his colleagues, as well as Langer and her associates [52]. Kabat-Zinn's conceptualization was termed as "meditative-mindfulness" and Langer's scholarly approach was termed as "creativemindfulness." Whereas Kabat-Zinn highlighted mindfulness' meta-cognitive aspects (i.e., acceptance, non-striving/non-judgmental), Langer emphasized mindfulness' awareness of external surroundings and inventive aspects that form the basis of creativity [52].

Meditative-mindfulness, drawing from ancient Buddhist tradition, approaches mindfulness as present-moment nonjudgmental awareness [53]. On the other hand, creativemindfulness views mindfulness as a flexible state of mind that is engaged in the present and its surroundings with four main components: engagement, seeking novelty, novelty producing, and flexibility [54,55]. Langer advanced the idea that mindfulness and creativity are naturally partners, as the principal characteristic of mindfulness-openness to novel ideas-initiates key cognitive processes for creativity (e.g., divergent and convergent thinking, flexibility, and ideational productivity) [56]. High-quality relationships between leaders and members stimulates a work context where non-judgments and secure climate for expressing opinions or developing new work procedures by employees are ensured. In addition, these leadership relationships provide workers with the required resources to allow reflectiveness and openness to novel ideas about tasks and goals. The immersion 
of tasks and the full awareness that characterizes mindfulness require a certain level of confidence and support from leadership.

In addition, mindfulness facilitates engagement and innovative behaviors. One of mindfulness' main components-decreased discursive thought—enables the individual to experientially be present in the current moment without any language [57]. Language establishes a rigid and evaluative mode of mental processes that crystalizes thought and compromises the cognitive flexibility that facilitates making "the creative leap" [58], aligning with previous findings that verbalizing problem-solving strategies impaired performance on creativity questions [59]. A multilevel meta-analysis found a significant correlation between mindfulness and creativity [60]. A study with two field experiments provided evidence of a relationship between mindfulness, creativity, and perceived competence [61]. A series of four studies found that one particular mindfulness skill—observing and attending to multiple stimuli-consistently positively predicted creative performance [62]. Another study found that a five-week mindfulness training positively impacted creativity over time [63]. That is, mindfulness' attention-regulation capacities are significant for the creative process through the power to broaden attention and integrate more information [64]. Moreover, mindfulness has the ability to focus and immerse employees in their tasks, which in turn allows them to uncover novelties in their work activity [65]. This study uses this foundational link with creativity to further close the gap in the mindfulness-innovative behavior line of research.

Another main component of mindfulness-attention regulation-enables the individual to control focus level and attention breadth in order to optimize goal-directed behavior [66]. This allows more mindful employees to more effectively engage in complex cognitive tasks [67].

Mindfulness has predicted work engagement, as mediated by authentic functioning [65]. Engagement can be conceptualized as full attention on tasks [68,69] and as "a positive, fulfilling, work-related state of mind that is characterized by vigor, dedication, and absorption" [70] (p. 74). Moreover, other underlying mechanisms (i.e., positive job-related affect and psychological capital) through which mindfulness positively predicts work engagement were identified [71]. Through a mindfulness-based intervention called Mindfulness in Motion, delivered to employees working in intensive care units, a chronically high-stress work environment, the intervention group's work engagement significantly increased after their eight-week series of sessions [72]. Moreover, in a recent meta-analysis of randomized controlled trials, mindfulness-based programs not only significantly improved employee mindfulness, but also significantly increased work engagement [73]. Mindfulness could be seen as a cognitive resource that contributes to increasing employee control over job demands. Following the job demands-resources model, mindful strategies increase work engagement and other positive work outcomes [74].

Engagement is not only predicted by mindfulness, but also by LMX. Initially, a positive relationship between LMX quality and work engagement was found [75]. Further tests of the relationship between the two constructs found that LMX positively predicted employee job performance through work engagement [76]. That is, the mediation relationship between LMX and work engagement in predicting employee performance has already been established. In addition, a multilevel structural equation model concluded that high-quality LMX offered a more resourceful workplace environment, which consequently positively predicted follower job performance, as mediated by job resources and work engagement [77]. This study established the double-mediation relationship between LMX as an independent variable and work engagement as the second mediator.

Moreover, in support of this positive predictive relationship between LMX and engagement, as well as engagement's mediating role in an extra-role performance outcome (e.g., innovative work behavior), a polynomial regression analysis of 280 dyads of leaders and subordinates found that LMX agreement between the two parties maximized work engagement and subsequent extra-role behavior [78]. High-quality leadership provides 
employees with resources that stimulates vigor, dedication, and absorption through the support from leaders and reciprocity of employees.

Finally, work engagement stimulates innovative behavior. High-quality LMX and high levels of mindfulness could be considered job resources to facilitate employee innovative behavior via engagement [79]. Using the job demands-resources model perspective, job resources have predicted extra-role performance through engagement [74]. A three-year longitudinal study found that job resources led to work engagement and work engagement led to personal initiative. Subsequently, personal initiative had a positive effect of workunit innovativeness over time [80]. One study found that work engagement was one of the two mediators between transformational leadership and innovative work behavior [81]. Another study offered concrete evidence with their finding that work engagement mediated the relationship between LMX and innovative work behavior [82]. This paper fills a research gap by incorporating mindfulness into this LMX-work engagement-innovative work behavior model, conceptualizing both mindfulness and work engagement as personal job resources that facilitate positive work outcomes.

In sum, the previously established predictive relationships between LMX and mindfulness, work engagement, and innovative work behavior, in addition to the predictive relationships between mindfulness and engagement and creative performance, form the basis of this study's hypothesized double-mediation model. Although there has been previous empirical support for the predictive nature of the relationships between these constructs, there is no one theory that can explain all of these inter-variable relationships. Only the job demands-resources model [74] had provided support for the relationship between job resources (i.e., mindfulness, as well as high-quality relationships, considered resources at work) and work engagement and performance (i.e., innovative behaviors). There still exists a gap in the literature that fails to connect all of these variables.

The present study investigates the relationship quality between leader and follower, as well as its ability to create a mindful space that promotes present-moment awareness and engagement, stimulating employees to focus on tasks, reflectiveness, and non-judgments and providing resources that facilitate engagement. In turn, mindfulness and engagement facilitate creativity and innovation. The purpose of this study is to examine leader-member exchange's (LMX) effects on innovative behavior mediated through mindfulness and engagement. That is, it is expected that workers with a higher-quality LMX, who are more mindful, will be more supported and engaged in their jobs, as demonstrated by their higher levels of innovation.

The main research questions ask: (1) Does mindfulness mediate the relationship between leader-member exchange and innovative behavior? (2) Does work engagement mediate the relationship between leader-member exchange, mindfulness, and innovative behavior?

The hypotheses (Figure 1) posit that the quality of leader-member exchange affects innovative behavior through a serial mediation with mindfulness and engagement:

Hypothesis 1 (H1). There is a significant indirect effect of LMX, through mindfulness at T2, on innovative work behavior at $\mathrm{T} 2$.

Hypothesis 2 (H2). There is a significant indirect effect of $L M X$, through work engagement at T2, on innovative work behavior at $\mathrm{T} 2$.

Hypothesis 3 (H3). There is a significant indirect effect of $L M X$, through mindfulness at $T 2$ and work engagement at $T 2$, on innovative work behavior at $T 2$. 


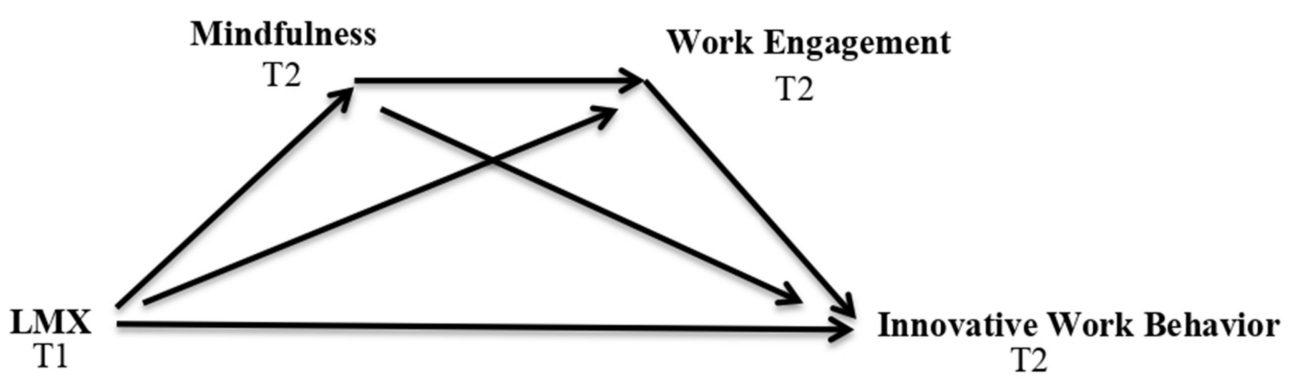

Figure 1. Hypothesized model: double-mediation model.

\section{Materials and Methods}

\subsection{Participants}

Using a between-subjects, two-wave longitudinal design with two data collections periods (T1: January-July 2014 and T2: 6 months later in July 2014-January 2015), the present study sampled 371 employees from 17 Spanish organizations from a variety of sectors, such as health services (i.e., public hospitals), education (i.e., public primary and middle schools), manufacturing (i.e., private e-health device companies), and the agro-food sector (i.e., private food-industry companies). Thirty companies were solicited from a list of companies in the Aragón region in Spain. The company response rate was 56.7\%.

All participation was voluntary without compensation as outlined in the informed consent at the beginning of the survey. The participants completed an anonymous penand-paper survey with a unique subject ID identifier. They were allowed to complete surveys during work hours or outside of the office after work hours. The employees completed all four scales at both T1 and T2. A period between four and six months between both data collections was decided to allow some time variation on the study variables, without reducing rotation of workforce. This time delay allowed lagged effects of antecedents on innovation behaviors to be captured. It should be noted that all measures (original versions in English) were translated into Spanish. Then, two bilingual (SpanishEnglish) speakers tested the equivalence of all items in both languages-rewording items as necessary. Participants answered demographic questions at the end of the questionnaire after the four main scales.

In T1, 124 of the participants were male (33.4\%), 198 were female (53.4\%), and 49 did not specify their gender (13.2\%). In T2, 86 participants were male (34.1\%), 165 were women $(65.5 \%)$, and 1 did not specify their gender $(0.4 \%)$. Due to the $25 \%$ attrition rate between the two data collections, T2 included 252 employees.

All participants who did not complete all of the variables for each time period were deleted from the database. However, two participants who did not have data for LMX at T2 were included in the final database. That is, in the analyses, the final sample size included 210 employees who responded at both $\mathrm{T} 1$ and $\mathrm{T} 2$ (i.e., $\mathrm{N}=210$ ). After the data cleaning, there were 63 male $(30 \%), 116$ female $(55.2 \%)$, and 31 participants without a specified gender $(14.8 \%)$. The ages ranged from 22 to $62(\mathrm{M}=41.49 ; \mathrm{SD}=10.61)$, and job tenure ranged from 0 to 36 years $(\mathrm{M}=8.67$; $\mathrm{SD}=7.81)$.

\subsection{Measures}

Leader-Member Exchange (LMX). LMX quality between the employees and their supervisors was operationalized through a 7-item Leader-Member Exchange (LMX-7) [83]. The LMX-7 is the most commonly used measure of leadership relation quality [84] and also the strongest LMX scale psychometrically [19]. Participants rated their level of agreement with each of the items with a 7-point Likert scale ranging from "To a Very Low Degree" (1) to "To a Very High Degree" (7). An example item included, "My supervisor would be personally inclined to help me solve problems in my work." All item scores were summed 
and averaged for a final scale score. Higher scores indicated higher-quality LMX. The Cronbach's alpha was 0.96 for both T1 and T2.

Mindfulness. The reduced 5-item State-Mindfulness Attention Awareness Scale (MAAS) assessed individual mindfulness levels among the employees, which included the items that explained the most scale variance [85]. This scale has demonstrated high reliability and strong convergent validity with trait mindfulness, as assessed by the 15-item MAAS $[85,86]$. Instructed to think about their specific experiences in the workplace, subjects rated their levels of agreement using a 6-point Likert scale ranging from "Almost Never" (1) to "Almost Always" (6). A sample item was, "I do jobs or tasks automatically, without being aware of what I am doing." All item scores were summed and averaged for a final scale score. It should be noted that scores were reverse coded so that higher scores indicated higher levels of mindfulness. The Cronbach's alpha was 0.78 for T1 and 0.79 for T2.

Work Engagement. A reduced 13-item version of the 17-item Utrecht Work Engagement Scale (UWES) operationalized engagement with three sub-dimensions: vigor, dedication, and absorption [87]. In addition to its typically high internal consistencies in past investigations (0.80-0.90), the UWES has been validated across various samples from a range of countries, including China, Japan, Argentina, France, Finland, the Netherlands, Belgium/Flanders, and Spain [88-92]. Thus, it has been used as an unbiased instrument across racial groups [87]. Participants rated the level of frequency that they had experienced the various statements on a 7-point Likert scale ranging from "Never" (1) to "Always" (7). An example item was, "I can continue working for very long periods at a time." All item scores were summed and averaged for a final scale score. Higher scores indicated higher levels of engagement. The Cronbach's alpha was 0.89 for T1 and 0.90 for T2.

Although 13 items were collected, the analysis included the eight items from the vigor and dedication subscales. The absorption subscale was the most recent subscale to be added to the original two subscales [70]. Nevertheless, the crucial items of UWES were vigor and dedication. Absorption was not a unique dimension of engagement that loaded onto the latent workaholism factor in addition to the latent work engagement factor [93]. Other researchers also found the two- factor model to be superior to the one-factor and three-factor models, in which vigor and dedication loaded onto one factor and absorption loaded onto the second factor [91]. A further item response modeling analysis supported a unidimensional interpretation over a multidimensional interpretation and a single global score, since strong factor correlations would offer little incremental predictive value [94]. The Cronbach's alpha for the 8-item version was 0.87 for both T1 and T2.

Innovative Work Behavior (IWB). A 9-item scale for innovative behavior operationalized innovative work behavior [95], based on 41. Employee ratings and supervisor ratings of the employees' innovative behavior were significantly correlated $(\mathrm{r}=0.35, p<0.001)$, supporting the validity of this measure [96]. A significant correlation between a similar innovative work behavior scale (supervisor-rated) and an objective measure of invention disclosures from the company's archives was found $(r=0.33, p<0.001)$ [41]. Participants rated their level of frequency of performing the activity with a 7-point Likert scale ranging from "Never" (1) to "Always" (7). Three items referred to idea generation (e.g., "Creating new ideas for difficult issues"), three to idea promotion (e.g., "Mobilizing support for innovative ideas"), and three to idea realization (e.g., "Transforming innovative ideas into useful applications"). All item scores were summed and averaged for a final scale score. Higher scores indicated higher levels of innovative work behavior. The Cronbach's alpha was 0.94 for $\mathrm{T} 1$ and 0.95 for T2.

\subsection{Procedure}

Following Bennett's recommendation [97], the amount of missing data (i.e., 63 item non-responses among 38 participants) was less than $10 \%$ of the data; thus, a multiple imputation approach was used by replacing the scale items with the individual's particular scale mean (i.e., person mean substitution or valid mean substitution). 
Reliability and correlational analyses were conducted using SPSS (version 24). In order to conduct the confirmatory factor analysis and test the double mediation posited by Hypotheses 1-3, the data were analyzed using structural equation modeling (SEM) with Mplus 7.3. SEM with latent variables tested the three hypotheses of the study. LMX at T1 was the independent variable, mindfulness at T2 was the first mediator, work engagement at T2 was the second mediator, and innovative work behavior at T2 was the dependent variable. The baseline of the dependent variable was controlled for using innovative work behavior at T1. The statistical significance of the three indirect effects was evaluated based on a $95 \%$ confidence interval. If the $95 \%$ confidence interval did not include zero, the indirect effect was considered to be significant at the 0.05 -level.

\section{Results}

Validity. A confirmatory factor analysis (CFA) was carried out on the 8 UWES items to ensure that a one-factor structure would fit the data well using the software Mplus 7.3. The estimation method was maximum likelihood (ML); the error covariance was freed between VIG02 and DED05. According to the CFA results, all fit indices demonstrated that the two-factor structure fit the data, except one: $\chi^{2}(18, \mathrm{~N}=210)=56.53, p<0.001$; $\mathrm{CFI}=0.95 ; \mathrm{TLI}=0.93 ; \mathrm{RMSEA}=0.10 ; \mathrm{SRMR}=0.05$. It should be noted that it is possible that the model did not produce the ideal RMSEA value of less than 0.08 because this fit index is particularly sensitive to sample size $(\mathrm{N}=210)$. The average standardized factor loading was 0.71 , ranging from 0.45 to 0.86 . Both vigor and dedication shared a high latent factor correlation of 0.85 , which suggested that the two subscales measured extremely similar constructs. Additionally, the one-factor structure had similar results as the twofactor structure: $\left(\chi^{2}(19, \mathrm{~N}=210)=60.57, p<0.001\right.$; CFI $=0.95$; TLI $=.93$; RMSEA $=0.10$; SRMR $=0.04)$. The average standardized factor loading was 0.60 , ranging from 0.33 to 0.79 . Thus, the previously stated results and latent factor correlation supported the use of a unidimensional structure in the double-mediation model.

Relationship between LMX and Other Study Variables. Table 1 reports descriptive statistics and bivariate correlations between LMX quality and the other study variables. LMX quality at T1 significantly correlated positively with mindfulness (i.e., MAAS), work engagement (i.e., UWES), and IWB at both T1 and T2. Mindfulness at T2 shared significant positive correlations with all study variables at both T1 and T2. Work engagement at T2 significantly correlated positively with all study variables except mindfulness at T1.

Furthermore, IWB shared significant positive correlations with all study variables at both $\mathrm{T} 1$ and T2, except with mindfulness at T2. These correlations all provided promising initial support for the significance of the hypothesized double-mediation model.

Effect of LMX on IWB through Mindfulness and Work Engagement. To test the three hypotheses, a SEM analysis was conducted. The latent variables included LMX quality (i.e., LMX), mindfulness (i.e., MAAS), work engagement (i.e., UWES), and innovative work behavior (i.e., IWB). The SEM's latent variables were built using a parceling technique [98]. The latent variables were created by using two parcels for each observed variable. Each parcel included half of the scale items. For instance, the LMX latent variable included four items in one parcel (i.e., LMX_A) and three items in the other parcel (i.e., LMX_B) from the LMX scale. The two UWES parcels were divided by their subscales: vigor and dedication.

After controlling for the baseline effects of the dependent variable at T2 (i.e., partial out the effects of IWB at T1 from IWB at T2), the results of the SEM analysis showed an acceptable model fit to the data: $\chi^{2}(28, \mathrm{~N}=210)=92.13, p<0.001$; CFI $=0.95$; TLI $=0.92$; RMSEA $=0.10 ;$ SRMR $=0.10$. Again, it should be noted that the model did not produce the ideal RMSEA and SRMR values of less than 0.08 due to those two fit indices' sensitivity to sample size $(\mathrm{N}=210)$. The standardized loadings, the $\mathrm{R}^{2}$ values, and their significance are included in the model presented in Figure 2. 
Table 1. Means, standard deviations, and correlations between study variables at $\mathrm{T} 1$ and $\mathrm{T} 2$.

\begin{tabular}{ccccccccc}
\hline Variables & M (SD) & $\mathbf{1}$ & $\mathbf{2}$ & $\mathbf{3}$ & $\mathbf{4}$ & $\mathbf{5}$ & $\mathbf{6}$ & $\mathbf{7}$ \\
\hline 1. LMX (T1) & $5.09(1.51)$ & & & & & & & \\
2. MAAS (T1) & $4.77(0.84)$ & $0.24^{* *}$ & & & & & & \\
3. UWES (T1) & $5.30(0.96)$ & $0.41^{* *}$ & $0.28^{* *}$ & & & & & \\
4. IWB (T1) & $4.18(1.25)$ & $0.19^{* *}$ & 0.09 & $0.47^{* *}$ & & & & \\
5. LMX (T2) & $5.13(1.41)$ & $0.67^{* *}$ & $0.15^{*}$ & $0.31^{* *}$ & 0.11 & & & \\
6. MAAS (T2) & $4.73(0.86)$ & $0.24^{* *}$ & $0.57^{* *}$ & $0.27^{* *}$ & $0.18^{* *}$ & $0.21^{* *}$ & & \\
7. UWES (T2) & $5.21(0.99)$ & $0.26^{* *}$ & 0.09 & $0.64^{* *}$ & $0.38^{* *}$ & $0.34^{* *}$ & $0.28^{* *}$ & \\
8. IWB (T2) & $4.27(1.23)$ & $0.18^{* *}$ & $0.15^{*}$ & $0.35^{* *}$ & $0.55^{* *}$ & $0.16^{*}$ & 0.12 & $0.51^{* *}$ \\
\hline
\end{tabular}

Note. $M$ and SD are used to represent mean and standard deviation, respectively. ${ }^{*}$ Indicates $p<0.05 .{ }^{* *}$ Indicates $p<0.01$.

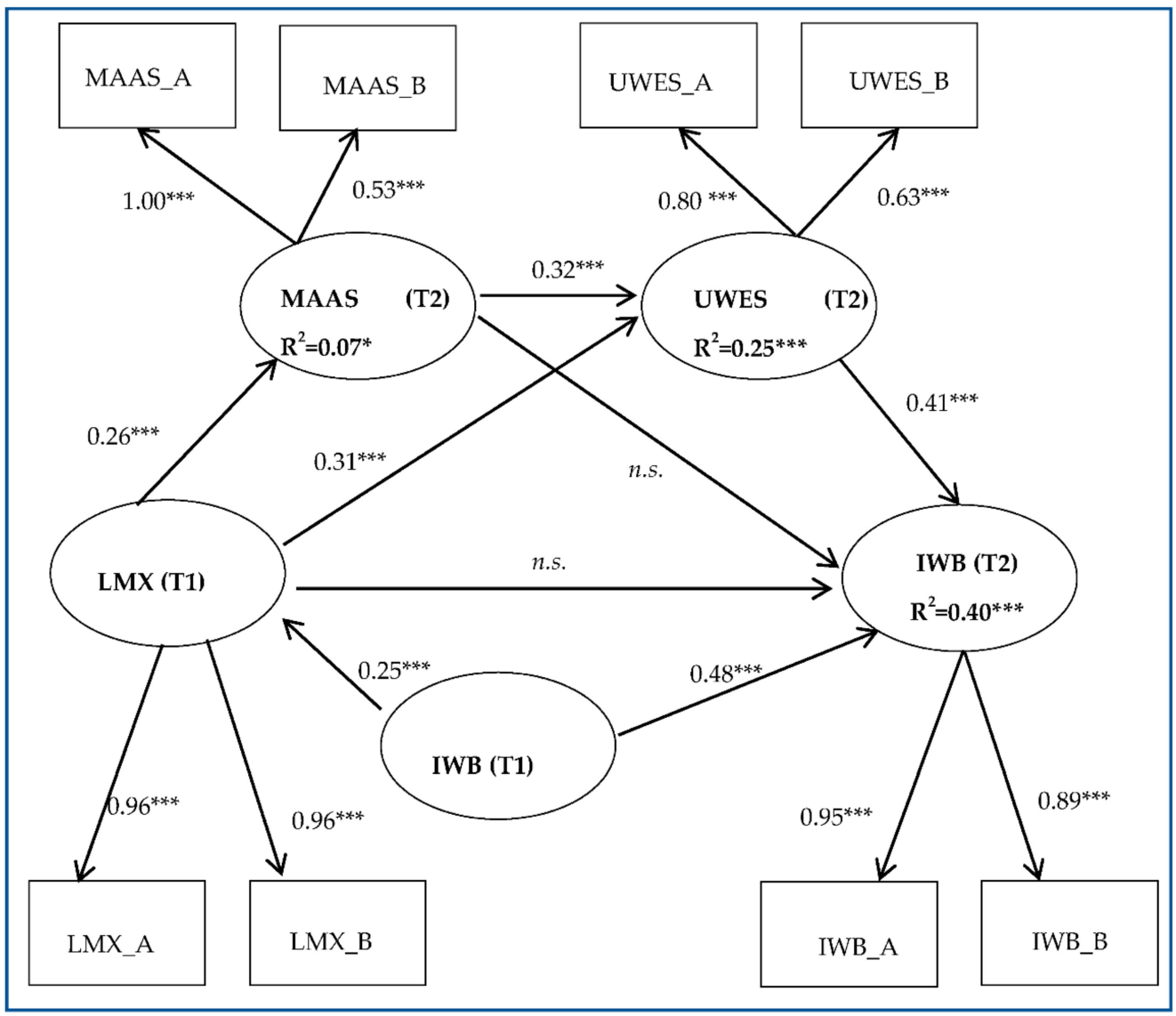

Figure 2. Structural Equation Model with Latent Variables $\left({ }^{*} p<0.05 ;{ }^{* * *} p<0.001\right)$.

All standardized loadings were significant at the 0.001 level, except the pathway from mindfulness to innovative work behavior (IWB) and from LMX to IWB (i.e., the direct effect). The first indirect effect of mindfulness on IWB was significant $(B=0.052,95 \%$ CI $(0.016,0.088))$, which led to the acceptance of Hypothesis 1 . The second indirect effect of work engagement on IWB was also significant $(B=0.16,95 \% \mathrm{CI}(0.055,0.27))$, which led to the acceptance of Hypothesis 2. Furthermore, the third indirect effect of mindfulness and work engagement on IWB was significant $(B=0.027,95 \%$ CI $(0.004,0.050))$, which led to the acceptance of Hypothesis 3. Mindfulness mediated the effect of LMX on IWB. Work engagement mediated the effect of LMX on IWB. Additionally, LMX positively affected IWB through mindfulness and work engagement. With all three significant indirect effects, all three hypotheses were supported.

Due to the non-significant direct effect, the data suggested a full mediation of the effect of LMX on IWB through its two mediators, mindfulness and work engagement. That 
is, the effect of LMX on IWB was statistically fully explained through the serial mediation of mindfulness and work engagement.

\section{Discussion}

The aim of the present study was to evaluate the underlying mechanisms by which high quality leader-member exchange (LMX) affects innovative work behavior (IWB) and to establish an empirical link between LMX, mindfulness, work engagement, and IWB. Results of the current study suggest that high quality leader-member exchanges are positively related to IWB. After controlling for the effects of baseline scores of IWB at T2, high-quality LMX showed a positive effect on IWB. Moreover, the relationship was fully mediated by both mindfulness and work engagement. We postulate that high quality leader-follower relationships resulted in an increase in follower mindfulness, as well as an increase in follower work engagement, which in turn led to a subsequent increase in follower innovation behaviors in the workplace.

It should be noted that LMX did not have a significant effect on IWB, nor did mindfulness have a significant positive effect on IWB, even though it mediated the relationship between LMX and IWB. This is logical since the results suggest a full double mediation, which supports the originally proposed model of this study. Additionally, previous research already supports the LMX-creativity/innovation and the mindfulness-creativity/innovation relationship [99-107]. Thus, the non-significant direct effect (i.e., LMX-IWB) and nonsignificant effect of the first mediator on the dependent variable (i.e., mindfulness-IWB) does not signal a null relationship, but rather a complete explanation of the effect of LMX on IWB by the two mediators. This study highlights two mechanisms by which LMX positively affects IWB: mindfulness and work engagement. The findings reveal the mediating role of mindfulness between LMX and IWB, the mediating role of work engagement between LMX and IWB, and the double mediating role of mindfulness and work engagement between LMX and IWB. The results of this two-wave longitudinal study suggest that high-quality LMX has a positive effect on mindfulness, which is consistent with previous evidence that supports the association between mindfulness and LMX [108]. A possible explanation is that the mutual support, trust, and respect associated with high-quality leader-member exchanges set the adequate social and cognitive environment for employees to be aware of their external surroundings and to be open to novel ideas (i.e., demonstrate higher levels of mindfulness). Not only did LMX have a positive effect on mindfulness, but also a positive effect on IWB through mindfulness. Mindfulness' mediating role between LMX and IWB is the first step in closing the gap in the literature that explains the effect of LMX on IWB through mindfulness. The results indicate that rich leader-follower relationships contribute to the follower's elevated external awareness and openness to novelty, which in turn facilitates higher levels of innovation in the workplace.

The findings also reveal that mindfulness has a positive effect on work engagement. This expands the literature that only focused on mindfulness as a mediator between work engagement and IWB $[78,101]$ and remains consistent with previous literature that established mindfulness' relationship with work engagement [71,109-111]. That is, this positive effect further verifies mindfulness (e.g., follower awareness) as a key to the link between the leader-follower match and work engagement [111].

The results further show that high-quality LMX has a positive effect on work engagement, which is consistent with previous findings [112]. Moreover, the results reveal that work engagement has a positive effect on IWB, supporting prior empirical results $[113,114]$. A possible explanation of this relationship is that more engaged individuals are more likely to relate to and partake in innovation processes [113]. Additionally, LMX's positive effect on IWB can be explained through work engagement. The mediating role of work engagement between LMX and IWB is congruent with previous studies that offered support for the same LMX-work engagement-IWB mediation pathway [82,115]. This emphasizes the crucial role leaders play in not only supporting their followers, but also nurturing work engagement. 
The effects of high-quality LMX, including this study's findings, support the longstanding notion that high-quality leader-follower relationships positively relate to follower creativity [116]. That is, employees who maintain high-quality relationships with their supervisors benefit from an enabling effect for innovation [116]. High-quality LMX fosters work environments with greater employee autonomy, support, and idea-generating behavior (i.e., information sharing) [117].

Perhaps employees with high-quality LMX relationships may be encouraged to feel comfortable enough to generate, promote, and realize creative ideas. Alternately, they may engage in more innovative behavior in order to reciprocate to their supervisor for the high-quality relationship [117]. This series of previously stated significant relationships advocates that high-quality leader-follower relationships (i.e., high-quality LMX) establish the social exchanges necessary to facilitate follower awareness and cognitive processes that cultivate creativity (i.e., mindfulness), which promotes an increased level of engagement in one's work (i.e., work engagement) and fosters innovative behavior in the workplace (i.e., innovative work behavior). The theoretical value of this study lies in the original mixture and empirical connection between all four of these constructs in a single double-mediation model as their explanation of the process by which LMX quality affects innovative work behavior.

The authors should discuss the results and how they can be interpreted from the perspective of previous studies and of the working hypotheses. The findings and their implications should be discussed in the broadest context possible. Future research directions may also be highlighted.

Practical Implications. This study's findings not only contribute important theoretical developments to the fields of leadership, mindfulness, and innovation, but also practical implications for the (modern and innovative) workplace. The findings are particularly relevant for organizations with innovation integrated into their business strategy as a stable source of sustainable growth and competitive advantage. To meet the ever-increasing innovation demands in the business market and workplace context, organizations will be able to turn to high-quality leadership relationships and mindfulness in order to facilitate innovation and maintain a competitive edge in the long run. These findings could justify the investment in company-wide programs to increase the quality of supervisor-employee relationships, introduce mindfulness practices to organizational members ranging from upper management to frontline workers, and ensure work engagement among all workers. For instance, to more effectively set the context for employee mindfulness, mindfulness should be integrated into leadership development. Sanyal and Rigg offered suggestions on how to integrate mindfulness into leadership programs based on the results of their empirical study [118].

The sustainability of companies relies both on continuous innovation and the wellbeing of employees. In this sense, our results suggest that programs for developing high-quality LMX and stimulating mindfulness at work add value for the increase and maintenance of innovative behaviors as well as promoting employees' well-being, at least in terms of work engagement. Thus, companies that introduce systematic actions to develop high-quality relationships and mindfulness could improve their innovation and health outcomes.

\section{Conclusions}

The results of the present study indicate that high-quality LMX is positively related to innovative behaviors through the serial mediation of mindfulness and work engagement. By relating these four distinct variables, this study makes enlightening contributions, both in theory, by closing literature gaps and offering evidence to further fortify previous empirical links, and in practice, by establishing key antecedents in the innovation process. This allows researchers and practitioners to better understand the importance of leaderfollower relationships and the way in which they can inspirit innovative behavior in an organization to gain a strategic advantage over market competitors. 
Limitations. This study presents a set of weaknesses. For instance, Langer's 14-item Mindfulness/Mindlessness Scale [55], more oriented to creativity-related characteristics (i.e., four subscales: Novelty Seeking, Engagement, Novelty Producing, and Flexibility), was not used to assess individual trait mindfulness among the employees in order to evaluate the effect of mindfulness on innovative behaviors. This may seem like a contradiction between the investigation's theoretical backbone and empirical operationalization. However, by using one of the most widely used trait mindfulness questionnaires (Mindful Attention Awareness Scale) [85], the study avoided including the second mediator (i.e., engagement) as a part of the first mediator's (i.e., mindfulness) fundamental theoretical and operational definition.

Additionally, there was a single source of data included in the model (i.e., self-reported data). A meta-analysis with 88 independent samples from 86 empirical articles compared the research results of the two types of employee creativity, self-ratings, and non-selfreport measures (i.e., supervisor ratings, peer ratings, and objective measures) [119]. The average age was 36 years old ( $\mathrm{SD}=8$ years), and the average organizational tenure was eight years. This meta-analysis measured the effect sizes of the creativity measures with respect to various personal characteristics (e.g., positive affect, education level, and intrinsic motivation to work) and contextual factors (e.g., supervisor support, transformational leadership, and LMX quality). On the other hand, the difference in effect size of LMX quality on self-rated creativity and non-self-reported creativity was not statistically significant.

Even though no differences were found in the research results between self-reported creativity and non-self-reported creativity [119] and most of the empirical studies used a cross-sectional design, common method variance still posed a potential threat to singlesource data [120]. Ng and Feldman cautioned researchers to pay special attention to the threat of common method variance with mediational effects, especially when participants complete the self-ratings of the variables simultaneously [119].

That is, the questionnaire respondents could experience an inescapable need to skew their ratings in order to maintain cognitive and/or attitudinal consistency in their responses. This is particularly common in cross-sectional studies. Thus, in order to avoid common method bias, consistency motif bias, and implicit theories, as well as to provide a richer source of data not subject to social desirability bias, supervisor ratings of the employees' innovative behavior may provide richer and more accurate findings [119]. Nevertheless, by implementing a two-wave longitudinal design, this study followed one of the recommended remedies to address common method bias [120].

An additional potential weakness was the fact that the two mediators were not temporally separated from each other or from the dependent variable. An ideal longitudinal design for this double-mediation model would have been to have four data waves so that the independent variable, the two mediators, and the dependent variable were all collected in a specific time point. However, this two-time-point design offered a key advantage over a cross-sectional design in which the independent variable was temporally distinct from its mediators and the dependent variable.

This study does not include the specific leadership styles present in the various exchanges between employees and their supervisors. Thus, it should be noted that a leader who does not promote values and climates in alignment with mindfulness' fundamental features will not effectively create an environment conducive to member/employee mindfulness. However, one study yielded results in support of leader mindfulness predicting transformational leadership behaviors [121]. This study ran additional analyses to estimate the correlations between leader mindfulness and six sub-dimensions of transformational leadership, which included innovation $(r=0.27, p<0.05)$. That is, mindfulness at both the leader and the follower level may possess the potential to cultivate and inspirit innovation in the workplace. The use of innovative mindfulness was recommended [122], because the strategic leader not only acts as a top-down envisioning transformational leader, but also a bottom-up facilitating servant leader to facilitate innovative product differentiation. Furthermore, LMX mediated the relationship between transformational leadership and in- 
novative behavior [105], which further supports the strong association between the specific transformational leadership style, high-quality LMX, and IWB.

Finally, it should be noted that LMX might not be the most effective leadership approach to use in the 21st century. A cross-generational study found that millennials preferred a distinct leadership style (i.e., participative leadership) to that of Generation $X$ and baby boomers [123]. Other authors [124] noted that contemporary leadership theories, such as LMX, authentic leadership, and ethical leadership, may not appeal to the new millennial generation due to their increased individualism, decreased work centrality, increased focus on work-life balance, increased extrinsic motivation, and increased entitlement. For instance, the millennial workforce may not want to take the extra time required to engage in high-quality LMX, may be more interested in maintaining a healthy work-life balance than engaging in high-quality LMX, may be too focused on extrinsic reward to want to invest the necessary time to create and maintain high-quality LMX, and may be generally less interested in being led by a leader [124]. Thus, going forward, leaders should keep in mind the mindset of their followers/group members and adapt their leadership style to the distinct needs of the specific workforce.

Future Directions. Multi-level analysis at the team and leader levels would be one of the next steps to further test the generalizability of this double-mediation model. A previous study [50] already found that LMX quality mediates the relationship between leader mindfulness and employee in- and extra-role performance. In the same vein, the concept of team mindfulness and its relationship with conflict transformation and social undermining was introduced in a three-wave study [125]. Furthermore, possible interventions could address high-quality LMX and mindfulness, such as a supervisorsupervisee mindfulness-based program.

A mindfulness-based mentoring program enhanced team performance after conducting four follow-up assessments every three months after the end of the intervention [126]. Thus, testing for the model's validity in the multi-level context of leadership and teams with respect to innovative behavior would not be an irrational investigative leap. Additionally, analyzing the three separate dimensions of innovation would be a way to further deepen our understanding of not only how LMX quality affects innovation, but also of what stage of innovation LMX quality particularly facilitates (e.g., idea generation, idea promotion, and idea realization).

A meta-analysis of LMX and culture across 23 countries found the relationship between LMX and organizational citizenship behavior to be stronger in horizontal-individualistic than vertical-collectivistic cultures [127]. The current study was conducted in Spain, a relatively more individualistic culture (i.e., more individualistic than Romania and China); thus, future studies should test the model's generalizability to different (i.e., collectivistic) cultures [128]. For instance, Spain, with an individualism score of 51 and a percentage of 69.3 employees with a good relationship with their supervisor, differs from Romania, with a lower individualism score of 30 and a lower percentage of 65.4 employees with a good relationship with their supervisor $[129,130]$.

Moreover, to expand the investigation's scope beyond European borders, a comparative study in China, with an individualism score of 20, may also offer intriguing insights into the leadership, mindfulness, and innovation processes inter-continentally and cross-culturally.

The alignment between organizational climate and leadership style affects organizational financial performance [131,132]. One study [131] used an information-processing perspective with a focus on the CEO's point of view, whereas another [132] incorporated charismatic, consideration, and initiating structure leadership into a leadership, organizational climate, store size, and financial performance model with a focus on the employees' point of view. However, both studies found that leadership impacts climate, which in turn contributes to the organization's performance. It would be insightful to include organizational performance variables as the next outcome step of the double-mediation model. 
In sum, the present study found evidence about the effects of high-quality member relationships on innovative work behaviors. Leader-member exchange favors the use of the mindfulness of employees towards work, increasing work involvement and stimulating employees' innovative behaviors. Thus, mindfulness (focusing on task improvements through reflectiveness and non-judgment) and engaging in tasks are mediation processes through which high-quality relations between leaders and team members stimulate organizational innovation. Improving leader-member relationships and the mindful orientation of employees to tasks contribute to the sustainability of organizations, as they increase employees' well-being (i.e., work engagement) and innovation.

Author Contributions: Conceptualization, R.M., P.M., A.Z. and J.R.; methodology, R.M., P.M., A.Z. and J.R.; statistical analysis, R.M.; investigation, R.M., P.M., A.Z. and J.R. All authors have read and agreed to the published version of the manuscript.

Funding: This research received no external funding.

Institutional Review Board Statement: This study follows the guidelines of the Ethical Research Committee of the University of Valencia. Explicit approval for workplace surveys is not required.

Informed Consent Statement: Informed consent was obtained from all subjects involved in the study.

Data Availability Statement: Data available upon request to second author (J.R.).

Conflicts of Interest: The authors declare no conflict of interest.

\section{References}

1. Aziz, N.N.A.; Samad, S. Innovation and competitive advantage: Moderating effects of firm age in foods manufacturing SMEs in Malaysia. Procedia Econ. Financ. 2016, 35, 256-266. [CrossRef]

2. Chahal, H.; Bakshi, P. Examining intellectual capital and competitive advantage relationship: Role of innovation and organizational learning. Int. J. Bank Mark. 2015, 33, 376-399. [CrossRef]

3. Coccia, M. Sources of technological innovation: Radical and incremental innovation problem-driven to support competitive advantage of firms. Technol. Anal. Strateg. Manag. 2017, 29, 1048-1061. [CrossRef]

4. Herrera, M.E.B. Creating competitive advantage by institutionalizing corporate social innovation. J. Bus. Res. 2015, 68, 1468-1474. [CrossRef]

5. Amarakoon, U.; Weerawardena, J.; Verreynne, M.L. Learning capabilities, human resource management innovation and competitive advantage. Int. J. Hum. Resour. Manag. 2018, 29, 1736-1766. [CrossRef]

6. Nieves, J.; Quintana, A. Human resource practices and innovation in the hotel industry: The mediating role of human capital. Tour. Hosp. Res. 2018, 18, 72-83. [CrossRef]

7. Noe, R.A.; Clarke, A.D.; Klein, H.J. Learning in the twenty-first-century workplace. Annu. Rev. Organ. Psychol. Organ. Behav. 2014, 1, 245-275. [CrossRef]

8. Prajogo, D.I.; Oke, A. Human capital, service innovation advantage, and business performance: The moderating roles of dynamic and competitive environments. Int. J. Oper. Prod. 2016, 36, 974-994. [CrossRef]

9. Bass, B.M.; Avolio, B.J. The implications of transactional and transformational leadership for individual, team, and organizational development. Res. Organ. Chang. Dev. 1990, 4, 231-272.

10. Li, H.; Wu, Y.; Cao, D.; Wang, Y. Organizational mindfulness towards digital transformation as a prerequisite of information processing capability to achieve market agility. J. Bus. Res. 2021, 122, 700-712. [CrossRef]

11. Al-Zu'bi, H.A. The role of mindfulness in strategic creativity: An empirical investigation. Int. J. Bus. Innov. Res. 2018, 15, 269-276. [CrossRef]

12. Krishnan, H.A. Mindfulness as a Strategy for Sustainable Competitive Advantage. Bus. Horiz. 2021. [CrossRef]

13. Kahn, R.L.; Wolfe, D.; Quinn, R.; Snoek, J.; Rosenthal, R. Organizational Stress: Studies in Role Conflict and Ambiguity; Wiley: New York, NY, USA, 1964.

14. Liden, R.C.; Sparrowe, R.T.; Wayne, S.J. Leader-member exchange theory: The past and potential for the future. Res. Pers. Hum. Resour. 1997, 15, 47-120.

15. Graen, G.B.; Uhl-Bien, M. The transformation of professionals into self-managing and partially self-designing contributions: Toward a theory of leader-making. J. Manag. Syst. 1991, 3, 33-48.

16. Martin, R.; Epitropaki, O.; Geoff, T.; Topakas, A. A review of Leader-Member Exchange (LMX) research: Future prospects and directions. Int. Rev. Ind. Organ. Psychol. 2010, 25, 35-88.

17. Dansereau, F.; Graen, G.; Haga, W.J. A vertical dyad approach to leadership within formal organizations. Organ. Behav. Hum. Perform. 1975, 13, 46-78. [CrossRef] 
18. Graen, G.B.; Uhl-Bien, M. Development of leader-member exchange (LMX) theory of leadership over 25 years: Applying a multi-level multi-domain perspective. Leadersh. Q. 1995, 6, 219-247. [CrossRef]

19. Gerstner, C.R.; Day, D.V. Meta-analytic review of leader-member exchange theory: Correlates and construct ideas. J. Appl. Psychol. 1997, 82, 827-844. [CrossRef]

20. Ilies, R.; Nahrgang, J.D.; Morgeson, F.P. Leader-member exchange and citizenship behaviors: A meta-analysis. J. Appl. Psychol. 2007, 92, 269. [CrossRef] [PubMed]

21. Naumann, S.E.; Bennett, N. A case for procedural justice climate: Development and test of a multilevel model. Acad. Manag. J. 2000, 43, 881-889.

22. González-Romá, V.; Peiró, J.M.; Tordera, N. An examination of the antecedents and moderator influences of climate strength. J. Appl. Psychol. 2002, 87, 465. [CrossRef]

23. Dragoni, L. Understanding the emergence of state goal-orientation in organizational work groups: The role of leadership and multilevel climate perceptions. J. Appl. Psychol. 2005, 90, 1084-1095. [CrossRef]

24. Kozlowski, S.W.; Doherty, M.L. Integration of climate and leadership: Examination of a neglected issue. J. Appl. Psychol. 1989, 74, 546. [CrossRef]

25. Ostroff, C.; Kinicki, A.J.; Tamkins, M.M. Organizational Culture and Climate. Handbook of Psychology; Borman, W.C., Ilgen, D.R., Klimoski, R.J., Eds.; Wiley: New York, NY, USA, 2003; Volume 12, pp. 565-593.

26. Pons, F.J.; Ramos, J. Influencia de los Estilos de Liderazgo y las Prácticas de Gestión de RRHH sobre el Clima Organizacional de Innovación. Rev. Psicol. Trab. Organ. 2012, 28, 81-98. [CrossRef]

27. Tordera, N.; González-Romá, V. Leader-member exchange (LMX) and innovation climate: The role of LMX differentiation. Span. J. Psychol. 2013, 16, E83. [CrossRef]

28. Wang, H.; Law, K.S.; Hackett, R.D.; Wang, D.; Chen, Z.X. Leader-member exchange as a mediator of the relationship between transformational leadership and followers' performance and organizational citizenship behavior. Acad. Manag. J. 2005, 48, 420-432. [CrossRef]

29. Eldor, L.; Harpaz, I. A process model of employee engagement: The learning climate and its relationship with extra-role performance behaviors. J. Organ. Behav. 2016, 37, 213-235. [CrossRef]

30. Somech, A.; Drach-Zahavy, A. Understanding extra-role behavior in schools: The relationships between job satisfaction, sense of efficacy, and teachers' extra-role behavior. Teach. Teach. Educ. 2000, 16, 649-659. [CrossRef]

31. Clarke, S. Safety leadership: A meta-analytic review of transformational and transactional leadership styles as antecedents of safety behaviours. J. Occup. Organ. Psychol. 2013, 86, 22-49. [CrossRef]

32. Zohar, D. The effects of leadership dimensions, safety climate, and assigned priorities on minor injuries in work groups. J. Organ. Behav. 2002, 23, 75-92. [CrossRef]

33. Bass, B.M.; Stogdill, R.M. Bass \& Stogdill's Handbook of Leadership: Theory, Research, and Managerial Applications; Simon and Schuster: New York, NY, USA, 1990.

34. Fairhurst, G.T. The leader-member exchange patterns of women leaders in industry: A discourse analysis. Commun. Monogr. 1993, 60, 321-351. [CrossRef]

35. Fairhurst, G.T. The Leader-Follower Communication. In Handbook of Organizational Communication, 2nd ed.; Sage: Newbury Park, CA, USA, 2000.

36. Gouldner, A.W. The norm of reciprocity: A preliminary statement. Am. Sociol. Rev. 1960, 25, 161-178. [CrossRef]

37. Blau, P. Power and Exchange in Social Life; Wiley: New York, NY, USA, 1964.

38. Austin, J.T.; Vancouver, J.B. Goal constructs in psychology: Structure, process, and content. Psychol. Bull. 1996, 120, 338. [CrossRef]

39. Dunegan, K.J.; Tierney, P.; Duchon, D. Perceptions of an innovative climate: Examining the role of divisional affiliation, work group interaction, and leader/subordinate exchange. IEEE Trans. Eng. Manag. 1992, 39, 227-236. [CrossRef]

40. Sanders, K.; Moorkamp, M.; Torka, N.; Groenveld, S.; Groenveld, C. How to support innovative behavior? The role of LMX and satisfaction with HR practices. Technol. Invest. 2010, 1, 59-68. [CrossRef]

41. Scott, S.G.; Bruce, R.A. Determinants of innovative behavior: A path model of individual innovation in the workplace. Acad. Manag. J. 1994, 37, 580-607. [CrossRef]

42. Amabile, T.M.; Conti, R.; Coon, H.; Lazenby, J.; Herron, M. Assessing the work environment for creativity. Acad. Manag. J. 1996, 39, 1154-1185.

43. Volmer, J.; Spurk, D.; Niessen, C. Leader-member exchange (LMX), job autonomy, and creative work involvement. Leadersh. $Q$. 2012, 23, 456-465. [CrossRef]

44. Van Dyne, L.; Jehn, K.A.; Cummings, A. Differential effects of strain on two forms of work performance: Individual employee sales and creativity. J. Organ. Behav. 2002, 23, 57-74. [CrossRef]

45. Atwater, L.; Carmeli, A. Leader-member exchange, feelings of energy, and involvement in creative work. Leadersh. Q. 2009, 20, 264-275. [CrossRef]

46. Hammond, M.M.; Neff, N.L.; Farr, J.L.; Schwall, A.R.; Zhao, X. Predictors of individual-level innovation at work: A meta-analysis. Psychol. Aesthet. Creat. Arts 2011, 5, 90. [CrossRef]

47. Amabile, T.M. How to Kill Creativity; Harvard Business Review: Boston, BA, USA, 1998; Volume 76, pp. 76-87.

48. Basu, R.; Green, S.G. Leader-member exchange and transformational leadership: An empirical examination of innovative behaviors in leader-member dyads. J. Appl. Soc. Psychol. 1997, 27, 477-499. [CrossRef] 
49. Vogus, T.J.; Sutcliffe, K.M. Organizational mindfulness and mindful organizing: A reconciliation and path forward. Acad. Manag. Learn. Educ. 2012, 11, 722-735. [CrossRef]

50. Reb, J.; Chaturvedi, S.; Narayanan, J.; Kudesia, R.S. Leader mindfulness and employee performance: A sequential mediation model of LMX quality, interpersonal justice, and employee stress. J. Bus. Ethics 2019, 160, 745-763. [CrossRef]

51. Glomb, T.M.; Duffy, M.K.; Bono, J.E.; Yang, T. Mindfulness at work. Res. Pers. Hum. Resour. Manag. 2011, 30, 115-157.

52. Hart, R.; Ivtzan, I.; Hart, D. Mind the gap in mindfulness research: A comparative account of the leading schools of thought. Rev. Gen. Psychol. 2013, 17, 453. [CrossRef]

53. Kabat-Zinn, J. Wherever You Go There You Are: Mindfulness Meditation in Everyday Life; Hyperion: New York, NY, USA, 1994.

54. Langer, E.J.; Moldoveanu, M. The construct of mindfulness. J. Soc. Issues 2000, 56, 1-9. [CrossRef]

55. Langer, E.J. Langer Mindfulness Scale User Guide and Technical Manual; IDS Publishing Corporation: Worthington, DC, USA, 2004.

56. Langer, E.J. On Becoming an Artist: Reinventing Yourself through Mindful Creativity; Ballantine Books: New York, NY, USA, 2006.

57. Goldin, P.; Ramel, W.; Gross, J. Mindfulness meditation training and self referential processing in social anxiety disorder: Behavioral and neural effects. J. Cogn. Psychother. 2009, 23, 242-257. [CrossRef]

58. Hayes, S.C.; Wilson, K.G. Mindfulness: Method and process. Clin. Psychol. Sci. Pract. 2003, 10, 161-165. [CrossRef]

59. Schooler, J.W.; Ohlsson, S.; Brooks, K. Thoughts beyond words: When language overshadows insight. J. Exp. Psychol. Gen. 1993, 122, 166-183. [CrossRef]

60. Lebuda, I.; Zabelina, D.L.; Karwowski, M. Mind full of ideas: A meta-analysis of the mindfulness-creativity link. Personal. Individ. Differ. 2016, 93, 22-26. [CrossRef]

61. Grant, A.M.; Langer, E.J.; Falk, E.; Capodilupo, C. Mindful creativity: Drawing to draw distinctions. Creat. Res. J. 2004, 16, 261-265. [CrossRef]

62. Baas, M.; Nevicka, B.; Ten Velden, F.S. Specific mindfulness skills differentially predict creative performance. Personal. Soc. Psychol. Bull. 2014, 40, 1092-1106. [CrossRef]

63. Byrne, E.K.; Thatchenkery, T. Cultivating creative workplaces through mindfulness. J. Organ. Chang. Manag. 2019, 32, 15-31. [CrossRef]

64. Kasof, J. Creativity and breadth of attention. Creat. Res. J. 1997, 10, 303-315. [CrossRef]

65. Leroy, H.; Anseel, F.; Dimitrova, N.G.; Sels, L. Mindfulness, authentic functioning, and work engagement: A growth modeling approach. J. Vocat. Behav. 2013, 82, 238-247. [CrossRef]

66. Kudesia, R.S. Mindfulness and Creativity in the Workplace. Mindfulness in Organizations: Foundations, Research, and Applications; Reb, J., Atkins, P.W.P., Eds.; Cambridge University Press: Cambridge, UK, 2015; pp. 190-212.

67. Brefczynski-Lewis, J.A.; Lutz, A.; Schaefer, H.S.; Levinson, D.B.; Davidson, R.J. Neural correlates of attentional expertise in long-term meditation practitioners. Proc. Natl. Acad. Sci. USA 2007, 104, 11483-11488. [CrossRef]

68. Hopstaken, J.F.; Van Der Linden, D.; Bakker, A.B.; Kompier, M.A. A multifaceted investigation of the link between mental fatigue and task disengagement. Psychophysiology 2015, 52, 305-315. [CrossRef]

69. Hopstaken, J.F.; Van Der Linden, D.; Bakker, A.B.; Kompier, M.A.; Leung, Y.K. Shifts in attention during mental fatigue: Evidence from subjective, behavioral, physiological, and eye-tracking data. J. Exp. Psychol. Hum. Percept. Perform. 2016, 42, 878. [CrossRef]

70. Schaufeli, W.B.; Salanova, M.; González-Romá, V.; Bakker, A.B. The measurement of engagement and burnout: A two sample confirmatory factor analytic approach. J. Happiness Stud. 2002, 3, 71-92. [CrossRef]

71. Malinowski, P.; Lim, H.J. Mindfulness at work: Positive affect, hope, and optimism mediate the relationship between dispositional mindfulness, work engagement, and well-being. Mindfulness 2015, 6, 1250-1262. [CrossRef]

72. Klatt, M.; Steinberg, B.; Duchemin, A.M. Mindfulness in Motion (MIM): An onsite mindfulness based intervention (MBI) for chronically high stress work environments to increase resiliency and work engagement. J. Vis. Exp. 2015, 101, e52359. [CrossRef]

73. Vonderlin, R.; Biermann, M.; Bohus, M.; Lyssenko, L. Mindfulness-based programs in the workplace: A meta-analysis of randomized controlled trials. Mindfulness 2020, 11, 1579-1598. [CrossRef]

74. Bakker, A.B.; Demerouti, E.; Verbeke, W. Using the job demands-resources model to predict burnout and performance. Hum. Resour. Manag. 2014, 43, 83-104. [CrossRef]

75. Christian, M.S.; Garza, A.S.; Slaughter, J.E. Work engagement: A quantitative review and test of its relations with task and contextual performance. Pers. Psychol. 2011, 64, 89-136. [CrossRef]

76. Li, X.; Sanders, K.; Frenkel, S. How leader-member exchange, work engagement and HRM consistency explain Chinese luxury hotel employees' job performance. Int. J. Hosp. Manag. 2012, 31, 1059-1066. [CrossRef]

77. Breevaart, K.; Bakker, A.B.; Demerouti, E.; Sleebos, D.M.; Maduro, V. Uncovering the Underlying Relationship between Transformational Leaders and Followers' Task Performance. J. Pers. Psychol. 2014, 13, 194-203. [CrossRef]

78. Matta, F.K.; Scott, B.A.; Koopman, J.; Conlon, D.E. Does seeing "eye to eye" affect work engagement and organizational citizenship behavior? A role theory perspective on LMX agreement. Acad. Manag. J. 2015, 58, 1686-1708. [CrossRef]

79. Montani, F.; Dagenais-Desmarais, V.; Giorgi, G.; Grégoire, S. A conservation of resources perspective on negative affect and innovative work behaviour: The role of affect activation and mindfulness. J. Bus. Psychol. 2018, 33, 123-139. [CrossRef]

80. Hakanen, J.J.; Perhoniemi, R.; Toppinen-Tanner, S. Positive gain spirals at work: From job resources to work engagement, personal initiative and work-unit innovativeness. J. Vocat. Behav. 2008, 73, 78-91. [CrossRef] 
81. Li, H.; Sajjad, N.; Wang, Q.; Muhammad Ali, A.; Khaqan, Z.; Amina, S. Influence of transformational leadership on employees' innovative work behavior in sustainable organizations: Test of mediation and moderation processes. Sustainability 2019, 11, 1594. [CrossRef]

82. Agarwal, U.A.; Datta, S.; Blake-Beard, S.; Bhargava, S. Linking LMX, innovative work behaviour and turnover intentions: The mediating role of work engagement. Career Dev. Int. 2012, 17, 208-230. [CrossRef]

83. Scandura, T.A.; Graen, G.B. Moderating effects of initial leader-member exchange status on the effects of a leadership intervention. J. Appl. Psychol. 1984, 69, 428. [CrossRef]

84. Paglis, L.L.; Green, S.G. Both sides now: Supervisor and subordinate perspectives on relationship quality. J. Appl. Soc. Psychol. 2002, 32, 250-276. [CrossRef]

85. Brown, K.W.; Ryan, R.M. The benefits of being present: Mindfulness and its role in psychological well-being. J. Personal. Soc. Psychol. 2003, 84, 822. [CrossRef]

86. Tanay, G.; Bernstein, A. State Mindfulness Scale (SMS): Development and initial validation. Psychol. Assess. 2013, 25, 1286-1299. [CrossRef]

87. Schaufeli, W.B.; Bakker, A.B.; Salanova, M. The measurement of work engagement with a short questionnaire: A cross-national study. Educ. Psychol. Meas. 2006, 66, 701-716. [CrossRef]

88. Fong, T.C.T.; Ng, S.M. Measuring engagement at work: Validation of the Chinese version of the Utrecht Work Engagement Scale. Int. J. Behav. Med. 2012, 19, 391-397. [CrossRef] [PubMed]

89. Shimazu, A.; Schaufeli, W.B.; Kosugi, S.; Suzuki, A.; Nashiwa, H.; Kato, A.; Sakamoto, M.; Amano, S.; Hirohata, K.; Goto, R. Work engagement in Japan: Validation of the Japanese version of the Utrecht Work Engagement Scale. Appl. Psychol. 2008, 57, 510-523. [CrossRef]

90. Zecca, G.; Györkös, C.; Becker, J.; Massoudi, K.; de Bruin, G.P.; Rossier, J. Validation of the French Utrecht Work Engagement Scale and its relationship with personality traits and impulsivity. Rev. Eur. Psychol. Appl. Eur. Rev. Appl. Psychol. 2015, 65, 19-28. [CrossRef]

91. Spontón, C.; Mendrano, L.A.; Maffei, L.; Spontón, M.; Castellano, E. Validación del Cuestionario de Engagement UWES a la población de trabajadores de Córdoba, Argentina [Validation of the Engagement Questionnaire UWES for the Population of Workers of Cordoba, Argentina]. Liberabit 2012, 18, 147-154.

92. Schaufeli, W.B.; Shimazu, A.; Hakanen, J.; Salanova, M.; De Witte, H. An Ultra-Short Measure for Work Engagement: The UWES-3 Validation across Five Countries. Eur. J. Psychol. Assess. 2017, 35, 577-591. [CrossRef]

93. Schaufeli, W.B.; Taris, T.W.; Van Rhenen, W. Workaholism, burnout, and work engagement: Three of a kind or three different kinds of employee well-being? Appl. Psychol. 2008, 57, 173-203. [CrossRef]

94. De Bruin, G.P.; Hill, C.; Henn, C.M.; Muller, K.P. Dimensionality of the UWES-17: An item response modeling analysis. SA J. Ind. Psychol. 2013, 39, 1148. [CrossRef]

95. Janssen, O. Fairness perceptions as a moderator in the curvilinear relationships between job demands, and job performance and job satisfaction. Acad. Manag. J. 2001, 44, 1039-1050.

96. Janssen, O. Job demands, perceptions of effort-reward fairness, and innovative work behavior. J. Occup. Organ. Psychol. 2000, 73, 287-302. [CrossRef]

97. Bennett, D.A. How can I deal with missing data in my study? Aust. N. Z. J. Public Health 2001, 25, 464-469. [CrossRef]

98. Bandalos, D.L. Is parceling really necessary? A comparison of results from item parceling and categorical variable methodology. Struct. Equ. Modeling A Multidiscip. J. 2008, 15, 211-240. [CrossRef]

99. Atitumpong, A.; Badir, Y.F. Leader-member exchange, learning orientation and innovative work behavior. J. Workplace Learn. 2018, 30, 32-47. [CrossRef]

100. Colzato, L.S.; Szapora, A.; Hommel, B. Meditate to create: The impact of focused-attention and open-monitoring training on convergent and divergent thinking. Front. Psychol. 2012, 3, 116. [CrossRef] [PubMed]

101. Montani, F.; Vandenberghe, C.; Khedhaouria, A.; Courcy, F. Examining the inverted U-shaped relationship between workload and innovative work behavior: The role of work engagement and mindfulness. Hum. Relat. 2019, 73, 59-93. [CrossRef]

102. Muñoz-Doyague, M.F.; Nieto, M. Individual creativity performance and the quality of interpersonal relationships. Ind. Manag. Data Syst. 2012, 112, 125-145. [CrossRef]

103. Ostafin, B.D.; Kassman, K.T. Stepping out of history: Mindfulness improves insight problem solving. Conscious. Cogn. 2012, 21, 1031-1036. [CrossRef]

104. Pan, W.; Sun, L.Y.; Chow, I.H.S. Leader-member exchange and employee creativity: Test of a multilevel moderated mediation model. Hum. Perform. 2012, 25, 432-451. [CrossRef]

105. Shunlong, X.; Weiming, Z. The relationships between transformational leadership, LMX, and employee innovative behavior. J. Appl. Bus. Econ. 2012, 13, 87-96.

106. Wang, C.J. Does leader-member exchange enhance performance in the hospitality industry? The mediating roles of task motivation and creativity. Int. J. Contemp. Hosp. Manag. 2016, 28, 969-987. [CrossRef]

107. Zhao, H.; Kessel, M.; Kratzer, J. Supervisor-subordinate relationship, differentiation, and employee creativity: A selfcategorization perspective. J. Creat. Behav. 2014, 48, 165-184. [CrossRef] 
108. Reb, J.M.; Chaturvedi, S.; Narayanan, J. The Benefits of Mindful Leadership: Examining LMX as Mediator and Job Complexity as Moderator. In Proceedings of the Annual Meeting of the Academy of Management, Research Collection Lee Kong Chian School of Business, Honolulu, HI, USA, 5-10 August 2005.

109. Atkins, P.W.B.; Hassed, C.; Fogliati, V.J. Mindfulness Improves Work Engagement, Wellbeing and Performance in a University Setting. In Flourishing in Life, Work, and Careers; Burke, R.J., Page, K.M., Cooper, C., Eds.; Elgar Publishing: Cheltenham, UK, 2015; pp. 193-209.

110. Bunjak, A.; Cerne, M. Mindfulness-The Missing Link in The Relationship between Leader-Follower Strategic Optimism (Mis) match and Work Engagement. Front. Psychol. 2018, 9, 2444. [CrossRef]

111. Petchsawang, P.; McLean, G.N. Workplace spirituality, mindfulness meditation, and work engagement. J. Manag. Spiritual. Relig. 2017, 14, 216-244. [CrossRef]

112. Hassan, A.; Jubari, I.H.A.A. Organisational justice and employee work engagement: LMX as mediator. J. Int. Bus. Entrep. Dev. 2010, 5, 167-178. [CrossRef]

113. Bhatnagar, J. Management of innovation: Role of psychological empowerment, work engagement and turnover intention in the Indian context. Int. J. Hum. Resour. Manag. 2012, 23, 928-951. [CrossRef]

114. Park, Y.K.; Song, J.H.; Yoon, S.W.; Kim, J. Learning organization and innovative behavior: The mediating effect of work engagement. Eur. J. Train. Dev. 2014, 38, 75-94. [CrossRef]

115. Garg, S.; Dhar, R. Employee service innovative behavior: The roles of leader-member exchange (LMX), work engagement, and job autonomy. Int. J. Manpow. 2017, 38, 242-258. [CrossRef]

116. Tierney, P.; Farmer, S.M.; Graen, G.B. An examination of leadership and employee creativity: The relevance of traits and relationships. Pers. Psychol. 1999, 52, 591-620. [CrossRef]

117. Khazanchi, S.; Masterson, S.S. Who and what is fair matters: A multi-foci social exchange model of creativity. J. Organ. Behav. 2011, 32, 86-106. [CrossRef]

118. Sanyal, C.; Rigg, C. Integrating mindfulness into leadership development. J. Manag. Educ. 2021, 45, 243-264. [CrossRef]

119. Ng, T.W.; Feldman, D.C. A comparison of self-ratings and non-self-report measures of employee creativity. Hum. Relat. 2012, 65, 1021-1047. [CrossRef]

120. Podsakoff, P.M.; MacKenzie, S.B.; Lee, J.Y.; Podsakoff, N.P. Common method biases in behavioral research: A critical review of the literature and recommended remedies. J. Appl. Psychol. 2003, 88, 879. [CrossRef] [PubMed]

121. Lange, S.; Bormann, K.C.; Rowold, J. Mindful leadership: Mindfulness as a new antecedent of destructive and transformational leadership behavior. Gr. Interakt. Organ. Z. Angew. Organisationspsychol. 2018, 49, 139-147. [CrossRef]

122. Gehani, R.R. Innovative strategic leader transforming from a low-cost strategy to product differentiation strategy. J. Technol. Manag. Innov. 2013, 8, 144-155. [CrossRef]

123. Kodatt, S. I understand" You": Leadership preferences within the different generations. In Proceedings of the European Conference on Management, Leadership \& Governance, Athens, Greece, 5-6 November 2009; pp. 61-65.

124. Anderson, H.J.; Baur, J.E.; Griffith, J.A.; Buckley, M.R. What works for you may not work for (Gen) Me: Limitations of present leadership theories for the new generation. Leadersh. Q. 2017, 28, 245-260. [CrossRef]

125. Yu, L.; Zellmer-Bruhn, M. Introducing team mindfulness and considering its safeguard role against conflict transformation and social undermining. Acad. Manag. J. 2018, 61, 324-347. [CrossRef]

126. Singh, N.N.; Singh, S.D.; Sabaawi, M.; Myers, R.E.; Wahler, R.G. Enhancing treatment team process through mindfulness-based mentoring in an inpatient psychiatric hospital. Behav. Modif. 2006, 30, 423-441. [CrossRef] [PubMed]

127. Rockstuhl, T.; Dulebohn, J.H.; Ang, S.; Shore, L.M. Leader-member exchange (LMX) and culture: A meta-analysis of correlates of LMX across 23 countries. J. Appl. Psychol. 2012, 97, 1097. [CrossRef]

128. Hofstede, G. Culture's Consequences: Comparing Values, Behaviors, Institutions and Organizations across Nations; SAGE: New York, NY, USA, 2001.

129. Hofstede Insights. Compare Countries. 2010. Available online: https://www.hofstede-insights.com/product/comparecountries / (accessed on 21 March 2019).

130. EUROSTAT. Employees Having a Good Relationship with Their Supervisor by Sex and Age. 2015. Available online: http: / / appsso.eurostat.ec.europa.eu/nui/show.do?dataset=qoe_ewcs_7a2\&lang=en (accessed on 6 June 2020).

131. Døjbak, H.D.; Burton, R.M.; Obel, B.; Lauridsen, J. How failure to align organizational climate and leadership style affects performance. Manag. Decis. 2008, 46, 406-432. [CrossRef]

132. Koene, B.A.; Vogelaar, A.L.; Soeters, J.L. Leadership effects on organizational climate and financial performance: Local leadership effect in chain organizations. Leadersh. Q. 2002, 13, 193-215. [CrossRef] 